\title{
Analisis Tingkat Kepuasan Pasien Atas Pelayanan Zaal Kebidanan dan Kandungan pada RSUD Hamba Muara Bulian
}

\author{
Ratna $^{1}$, Nadiatul Khoiroh ${ }^{2}$ \\ ${ }^{1,2}$ Sekolah Tinggi Ilmu Ekonomi Graha-Karya Muara Bulian Jambi \\ Correspondence email: ratna1@gmail.com
}

\begin{abstract}
One of the targets of Obstetrics and Gynecology at the general hospital of bulian estuary, namely increasing the level of patient satisfaction so that this becomes one of the indicators for measuring service quality. One of the main elements supporting the level of patient satisfaction is patients with their resources. The purpose of the study was to determine the level of patient satisfaction with the quality of care in obstetrics and gynecology at the general hospital of bulian estuary. Respondents were patients with obstetrics and gynecology at 75 general hospitals in the bulian estuary servants. Methods of collecting data using questionnaires, observation, documentation. To test the hypothesis, the technique used is path analysis. Research results: (1) the quality of services in obstetrics and gynecology is very good, (2) the level of patient satisfaction with obstetrics and gynecology is very good. Advice for obstetrics and gynecology public hospitals in bulian estuary servans must improve service quality and maintain then maintain existing quality must be done, so that customers or users of the hospital do not feel disappointed and the service users do not move elsewhere.
\end{abstract}

Keywords: satisfaction, services.

\section{PENDAHULUAN}

Zaal kebidanan dan kandungan merupakan tempat proses melahirkan yang di alami oleh wanita. Pada proses ini terjadi serangkai perubahan besar yang terjadi pada ibu untuk dapat melahirkan janinnya melalui jalan lahir. Tujuan dari adanya zaal kebidanan dan kandungan ini adalah mendorong kelahiran yang aman bagi ibu dan bayi sehingga dibutuhkan peran dari petugas kesehatan untuk mengantisipasi dan menangani komplikasi yang mungkin terjadi pada ibu dan bayi, sebab kematian ibu dan bayi sering terjadi terutama pada proses persalinan.

Menurut survey demografi kesehatan indonesia (SDKI) tahun 2012 angka kematian ibu (AKI) akibat persalinan ibu di indonesia masih tinggi yaitu 208/100.000 kelahiran hidup dan angka kematian bayi (AKB) 26/1.000 kelahiran hidup (Kemenkes RI,2013). Hal ini menuntun penyediaan pelayanan kesehatan rumah sakit untuk meningkatkan kualitas pelayanan yang baik.

Rumah sakit sebagai instusi yang bergerak di bidang pelayanan kesehatan mengalami perubahan, pada awal perkembangannya, rumah sakit adalah lembaga yang berfungsi social, tetapi dengan adanya rumah sakit umum dan swasta, menjadi rumah sakit lebih mengacu sebagai suatu industri yang bergerak dalam bidang pelayanan kesehatan dengan melakukan pengelolaan yang berdasar pada manajemen badan usaha. Seiring dengan itu, terjadi persaingan antara sesama rumah sakit baik milik pemerintah maupun rumah sakit milik swasta, semua berlomba-lomba untuk menarik konsumen agar menggunakan jasanya. Tuntunan terhadap pemakaian jasa pelayanan kesehatan terhadap kualitas pelayanan kesehatan rumah sakit telah menjadi masalah mendasar yang di hadapin sebagian besar rumah sakit. Oleh karena itu, rumah sakit dituntun untuk selalu menjaga kepercayaan konsumen dengan meningkatkan kualitas pelayanan.

Kualitas pelayanan merupakan suatu kewajiban yang harus dilakukan dengan sebaik mungkin oleh pemberi jasa agar memuaskan kebutuhan dan keinginan pasien. Kualitas berkaitan erat dengan dengan kepuasan pasien. Berdasarkan model kualitas jasa Parasuraman yang dikutip oleh Kotler dan Keller (2016:442) mengidentifikas lima dimensi kualitas jasa yaitu: bukti fisik (Tangibles), empati (Empathy), Kehandalan (Reliability), Ketanggapan (Responsivness), dan jaminan (Assurance). Sedangkan Kepuasan pasien adalah sebagai perasaan senang atau kecewa yang di dapatkan dengan membandingkan anatara kinerja dan ekspektasinya (Richard Oliver, dalam Fandy Tjiptono, 2015: 23). Kepuasan pasien dapat dilihat setelah pelanggan menggunakan jasa tersebut, menurut Kotler dan Keller (2016:155) pasien dinyatakan puas apabila: setia terhadap produk, adanya komunikasi dari mulut kemulut yang bersifat positif (word of mouth communication), dan perusahaan menjadi pertimbangan pertama ketika membeli produk lain.

Rumah sakit di tuntut untuk melakukan berbagai perbaikan dalam memberikan pelayanan, baik dalam bidang ketersediaan sumber daya manusia yang di miliki, ketersediaan peralatan yang semakin canggih, mutu dari pelayanan, maupun dari biaya pelayanan. Para dokter atau perawat harus mampu menggunakan peralatan dan obat-obat dengan baik dan benar agar tidak terjadi kesalahan dalam memberikan pelayanan. Karena jika ada kesalahan dalam menggunakan peralatan dan obat-obat maka sangat dapat memberikan hasil pelayanan yang mengecewakan pasien.

Jika hal ini sampai terjadi maka akan mempengaruhi kepuasan pasien. Untuk mendapatkan 
kualitas pelayanan tentu dokter atau perawat di tuntut untuk mampu meminimalisirkan kesalahan-kesalahan. Dengan memberikan hasil pelayanan yang baik kepada pasien maka pasien akan merasa puas dan percaya terhadap pelayanan yang telah diberikan oleh rumah sakit. Kepuasan pasien merupakan gambaran apakah kualitas rumah sakit sudah atau belum memenuhi harapan para pasien. Kepuasan pasien dapat di artikan kualitan pelayanan yang di rasa pasien setelah memperoleh pelayanan dari perawat atau dokter sama atau melebihi dari yang di harapkan sebelum memperoleh pelayanan dari dokter atau perawat dari yang di harapkan sebelum memperoleh pelayanan dari perawat atau dokter lebih rendah dari yang di harapkan maka berarti pasien tersebut tidak puas dan tidak percaya dengan pelayanan yang di berikan rumah sakit.

Kepuasan pasien diharapkan akan membuat pasien selalu menggunakan jasa rumah sakit tersebut dalam melakukan berobat. Upaya mempertahankan pasien/pelanggan harus mendapatkan prioritas yang lebih besar dibandingkan untuk upaya mendapakan pelanggan yang baru. Karena pelanggan murni yang terus menerus menggunakan jasa rumah sakit tersebut merupakan asset terbesar dalam memperoleh kepercayaan masyarakat.

Salah satu rumah sakit di Muara Bulian yang menjalankan fungsinya sebagai tempat untuk berobat yaitu rumah sakit umum hamba yang terletak di Jl.Prof. Dr. Sri Sudewi. Mengingat semakin meningkatnya persaingan dibidang rumah sakit. Sangatlah penting bagi rumah sakit hamba untuk mempertahankan dan meningkatkan kualitas pelayanan serta menanamkan kepercayaan yang sudah melekat di benak pelanggan sehinggah dapat memberikan kepuasan tersendiri kepada pelanggan.

\section{Pelayanan}

Pengertian pelayanan atau jasa adalah setiap tindakan atau kegiatan yang dapat ditawarkan oleh suatu pihak lain. Pada dasarnya tidak berwujud dan tidak mengakibatkan perpindahan kepemilikan apapun. Kotler dan Armstrong (2016:248) menyatakan"jasa merupakan aktivitas ekonomi yang hasilnya bukan berbentuk produk fisik dan kontruksi yang umumnya dihasilkan dikonsumsi secara bersamaan serta memiliki nilai tambah bagi konsumen.pelayanan memiliki karakteristik yang berbeda menurut dengan produk barang fisik menurut Rambat Lupiyoadi (2014) karekteristik pelayanan yaitu: intangibility (tidak terwujud), Unstobarity (tidak dapat disimpan) dan kostimuzation (Kostomisasi).

Prinsip kualitas pelayanan ada 6 yaitu: kepemimpinan, pendidikan, perencanaan strategis, review, komunikasi dan total human reward. Sedangkan dimensi kualitas pelayanan menurut pasuraman, ddk yang dikutip oleh fandy tjipono: (2012: 174). Yaitu:
Tangible (berwujud) misalnya penampilan karyawan pelayanan, peralatan modern, tempat parker. Reability (keandalan), responsiviness, assurance (jaminan dan kepastian) dan emphaty

\section{Kepuasan Pelanggan}

Menurut Kotler \& Armstrong (2012:36), nilai pelanggan adalah perbandingan pelanggan antara semua keuntungan dan semua biaya yang harus dikeluarkan untuk menerima penawaran yang diberikan. Jumlah biaya pelanggan adalah sekelompok biaya yang digunakan dalam menilai, mendapatkan dan menggunakan produk atau jasa. Karena kepuasan pelanggan sangat tergantung pada persepsi dan ekspektasi pelanggan, maka sebagai pemasok produk perlu mengetahui faktor-faktor yang mempengaruhinya.

Pelanggan yang puas adalah pelanggan yang berbagai kepuasan dengan penyedia jasa. Bahkan pelanggan yang puas akan berbagai rasa dan pengalaman dengan pelanggan lain. Ini akan menjadi referensi bagi perusaha atau instunsi yang bersangkutan, oleh karna itu baik pelanggan maupun penyedia jasa akan sama-sama diuntungkan apabila kepuasan terjadi. Dengan melihat hubungan ini jelaslah bahwa kepuasan pelanggan harus selalu menjadi tujuan dari setiap perusahaan.

Hal ini berarti kepuasan merupakan faktor kunci bagi pelanggan dalam melakukan pembelian ulang yang merupakan porsi terbesar dari volume penjualan perusahaan. Menurut produk dan jasa untuk dapat memuaskan kebutuhan pelanggan, perusahaan dapat melakukan dengan tahapan-tahapan sebagai berikut:

a. Mengetahui kebutuhan dan keinginan pelanggan

b. Mengetahui proses pengambilan keputusan

c. Membangun citra perusahaan

d. Membangun kesadaran akan pentingnya kepuasan pelanggan

Faktor menentukan tingkat kepuasan pelanggan dalam menentukan tingkat kepuasan pelanggan terdapat 5 faktor utama yang harus di perhatikan yaitu Kualitas produk, Kualitas pelayanan, emosional, harga dan biaya.

a. Menurut Schnaars dalam buku strategi pemasaran (2008:24) pada dasarnya tujuan dari suatu bisnis adalah untuk menciptakan para pelanggan merasa puas. Terciptanya kepuasan pelanggan dapat memberikan berberapa manfaat, diantaranya : Hubungan antara perusahaan dan pelanggan menjadi harmonis

b. Memberikan dasar yang baik untuk membeli ulang

c. Dapat mendorong terciptannya loyalitas pelanggan

d. Membentuk suatu rekomendasi atau mengusulkan dari mulut ke mulut yang menguntungkan bagi perusahaan

e. Reputasi perusahaan menjadi baik di mata pelanggan

f. Laba yang di peroleh dapat meningkat 


\section{Indikator Dari Kepuasan Pelanggan}

a. Pelanggan yang puas akan menceritakan hal pengalamannya kepada teman-temannya saudara atau orang lain. Dengan demikian pelanggan tersebut merupakan pengiklan yang baik bagi perusahaan dan perusahaan tidak perlu membayarnya.

b. Pelanggan yang puas tidak segan-segan untuk membayar produk atau jasa yang dia gunakan dengan harga yang lebih tinggi.

c. Pelanggan yang puas akan kembali lagi jika dia memerlukannya lagi.

d. Pelanggan yang puas tidak mudah tergoda untuk pindah produk atau jasa lain.

e. Perusahaan yang memiliki komitmen untuk memuaskan pelanggan biasanya juga menyediakan lingkungan kerja yang baik bagi karyawan karyawannya.

\section{METODE}

\section{Jenis Penelitian}

Jenis penelitian yang di lakukan adalah jenis penilitian deskritif kuantitatif menurut Sugiyono (2011:14) jenis deskriptif kuantitatif dapat di artikan sebagai jenis penelitian berdasarkan pada filfasat positivisme, digunakan untuk meneliti pada populasi dan sampel tertentu. Selanjutnya yang menjadi subjek merupakan pasien zaal kebidanan dan kandungan RSUD HAMBA Muara Bulian.

\section{Jenis dan Sumber Data}

\section{Jenis Data}

Menurut Arikunto (2010) data penelitian menurut jenis ada dua:

a. Data kualitatif adalah data yang bukan dalam bentuk angka atau tidak dapat dihitung dalam bentuk bilangan riil, dan diperoleh dari RSUD HAMBA Muara Bulian seperti gambaran umum rumah sakit,hasil kuesioner dan data-data lain yang menunjang penelitian.

b. Data kuantitatif adalah data yang diperoleh dalam bentuk angka-angka yang memiliki suatu hitung baku secara sistematis seperti jumlah perawat zaal kebidanan dan kandungan RSUD HAMBA Muara Bulian.

\section{Sumber Data}

a. Data primer dalah data yang diperoleh penulis melalui observasi atau pengamatan langsung dari lokasi objek penelitian dan lingkungan sekitar, baik itu melalui observasi, Kuesioner dan wawancara secara langsung dengan pasien zaal kebidanan dan kandungan RSUD HAMBA Muara Bulian serta pihak luar yang sesuai dengan kebutuhan dalam penelitian ini.

b. Data Sekunder adalah data yang diperoleh secara tidak langsung, yaitu data yang tersebut diperoleh penulis dari dokumen-dokumen instansi (dalam hal ini RSUD HAMBA Muara Bulian) dan buku-buku literatur yang memberikan infomasi tentang Periku Pemimpin, Komitmen guru, dan

\section{Metode Pengumpulan Data Penelitian}

a. Metode penelitian yang digunakan adalah metode Penelitian Lapangan (Field Research) yaitu penelitian yang dilakukan secara langsung guna untuk memperoleh data yang erat kaitannya dengan penelitian ini. Data dari lapangan dapat diperoleh dari wawancara,observasi dan angket.

b. Penelitian Kepustakaan (Library Research) yaitu, data diperoleh dengan cara membaca literaturliteratur, bahan referensi, bahan kuliah, dan hasil penelitian lainnya yang ada hubungannya dengan obyek yang diteliti. Hal ini dilakukan penulis untuk mendapatkan tambahan pengetahuan mengenai masalah yang sedang dibahasnya.

\section{Populasi dan Sampel \\ Populasi}

Populasi adalah keseluruhan dari objek yang diteliti, menurut Arikunto (2010:130) mendefinisikan populasi adalah keseluruhan subjek yang ada dalam penelitian. Populasi yang digunakan dalam penelitian ini adalah para pasienZaal Kebidanan Dan Kandungan Rumah Sakit Umum Hamba Muara Bulian, yang berada di Muara Bulian rata-rata sekitar $4-6$ orang pasien perhari sehingga dalam satu bulan pasien Zaal Kebidanan dan Kandungan Rumah Sakit Umum Hamba Muara Bulian.sebanyak: 5 × 30 hari $=150$ orang populasi.

\section{Sampel}

Menurut Arikunto (2010) yang menyatakan apabila subjeknya kurang dari 100 orang maka lebih baik di ambil semuanya, selanjutnya apabila lebih, dari 100 orang maka sampel, yang diambil $10-15 \%$ atau $20-50 \%$ atau lebih sebaai subjek penelitian. Maka dikarenakan populasi lebih dari 100 maka penulis mengambil sampel sebesar $50 \%$ dari 150 populasi yang di ambil dari defenisi Arikunto.

$0.50 \times 150=75$ sampel

Jadi di sini dapat dijelaskan bahwa jumlah sampel pada penelitian ini adalah sebanyak 75 sampel.

\section{Metode Analisis \\ Skala Pengukuran}

Setelah ditentukan item-item dari variabel yang ada, maka langkah selanjutnya adalah mengadakan pengukuran atas variabel tersebut dengan menggunakan skala likert yaitu skala yang didasarkan atas penjumlahan sikap responden dalam merespon pertanyaan berkaitan dengan indikator suatu variabel yang akan diukur, dalam hal ini responden diminta untuk 
menyatakan setuju atau tidak setuju terhadap setiap pertanyaan untuk keperluan analisis Kuantitatif( Arikunto, 2010 : 110 ), maka jawaban itu dapat diberi skor seperti dibawah ini:

Tabel 1. Skor jawaban analisis kualitatif

\begin{tabular}{cc}
\hline Pilihan Jawaban & Skor \\
\hline Sangat Setuju (SS) & 5 \\
Setuju (S) & 4 \\
Cukup Setuju (CS) & 3 \\
Tidak Setuju (TS) & 2 \\
Sangat Tidak Setuju (STS) & 1 \\
\hline
\end{tabular}

\section{Analisis Deskriptif Variabel}

Skala pengukuran yang digunakan untuk mengukur masing-masing variabel dengan menggunakan skala likert, Skala likert adalah suatu alat ukur yang digunakan untuk mengatur sikap dan persepsi seseorang atau sekelompok orang, mengenai fenomena social. Jawaban setiap item instrument yang digunakan adalah skala likert mempunyai gradasi dari sangat positif sampai sangat negatif, Dengan skala likert, maka variabel yang akan di ukur dijabarkan menjadi indikator variabel. Kemudian indikator tersebut dijadikan sebagai titik tolak untuk menyusun item-item instrument berupa pernyataan dan pertanyaan.

Pada penelitian yang menggunakan sejumlah responden sebagai sumber data, maka data yang akan terkumpul menjadi bilangan yang besar, bila rata-rata (menggunakan sistem indeks) akan menghasilkan data dalam bentuk pecahan atau bilangan berkoma, maka untuk mempermudah penafsirannya diperlukan bantuan rentang skala indeks. Cara yang dapat digunakan adalah metode intervalisasi data, dengan langkah sebagai berikut: a. Menentukan jumlah kelas interval (dinotasikan K), dimana jumlah kelas dalam penelitian ini ada 5 (lima kelas diantaranya SS, S, CS, TS, STS).

b. Menentukan rentang data hasil observasi (Range dinotasikan $\mathrm{R}$ ), dimana $\mathrm{R}=$ Nilai Observasi TerbesarNilai Observasi Terkecil, dalam penelitian ini, Nilai Observasi Terbesar $=5(\mathrm{SS})$ dan Nilai Observasi Terkecil $=1(\mathrm{STS})$, sehingga $\mathrm{R}=5-1=4$.

c. Menetukan panjang kelas tiap interval (Pk), dimana : $\mathrm{Pk}=\frac{R}{K}=\frac{4}{5}$ $\mathrm{Pk}=0,8$

d. Masukan hasil perhitungan ke tabel :

Tabel 2. Rentang Skala Analisis Deskriptif Kualitas Pelayanan Dan Kepuasan Pasien

\begin{tabular}{ccc}
\hline No & Rentang Skala & $\begin{array}{c}\text { Penilaian Kualitas Pelayanan } \\
\text { dan Kepuasan Pasien }\end{array}$ \\
\hline 1 & $1,00<$ Nilai Indeks $\leq 1,80$ & Sangat Tidak Baik \\
2 & $1,80<$ Nilai Indeks $\leq 2,60$ & Tidak Baik \\
3 & $2,60<$ Nilai Indeks $\leq 3,40$ & Cukup Baik \\
4 & $3,40<$ Nilai Indeks $\leq 4,20$ & Baik \\
5 & $4,20<$ Nilai Indeks $\leq 5,00$ & Sangat Baik \\
\hline
\end{tabular}

\section{HASIL DAN PEMBAHASAN}

Tanggapan Responden Terhadap Kualitas Pelayanan Pada Zaal Kebidanan Dan Kandungan Pada RSUD Hamba Muara Bulian

Untuk mengetahui tanggapan pelanggan tentang kualitas pelayanan pada zaal kebidanan dan kandungan pada rumah sakit umum hamba muara bulian, peneliti menggunakan daftar pertanyaan yang di ajukan kepada kuesioner maka dalam hal ini dijelaskan tanggapan pasien mengenai kualitas pelayanan pada zaal kebidanan dan kandungan pada RSUD Hamba Muara Bulian.

Tabel 3. Hasil Tanggapan Responden terhadap Kualitas Pelayanan

\begin{tabular}{|c|c|c|c|c|c|c|c|c|c|}
\hline \multirow{2}{*}{ No } & \multirow{2}{*}{ Pertanyaan } & \multicolumn{5}{|c|}{ Jumlah Skor } & \multirow{2}{*}{$\begin{array}{l}\text { Total } \\
\text { Skor }\end{array}$} & \multirow{2}{*}{$\mathrm{N}$} & \multirow{2}{*}{ Indeks } \\
\hline & & SS & S & $\mathrm{CS}$ & $\mathrm{TS}$ & TST & & & \\
\hline 1 & $\begin{array}{l}\text { Zaal kebidanan dan kandungan sudah memiliki } \\
\text { peralatan modren yang mumpuni demi } \\
\text { kelancaran perawat dan dokter dalam melayani } \\
\text { pasien }\end{array}$ & $\begin{array}{c}62 \\
(310)\end{array}$ & $\begin{array}{c}12 \\
(48)\end{array}$ & $\begin{array}{c}1 \\
(3)\end{array}$ & - & - & 361 & 75 & 4,81 \\
\hline 2 & $\begin{array}{l}\text { Perawat dan dokter memiliki penampilan rapi } \\
\text { dan profesional dalam melayani pasien }\end{array}$ & $\begin{array}{c}50 \\
(250)\end{array}$ & $\begin{array}{c}25 \\
(100)\end{array}$ & & - & - & 350 & 75 & 4,66 \\
\hline 3 & $\begin{array}{l}\text { perawat dan dokter melaksanakan pelayanan } \\
\text { dengan baik dan benar }\end{array}$ & $\begin{array}{c}34 \\
(170)\end{array}$ & $\begin{array}{c}40 \\
(160)\end{array}$ & $\begin{array}{c}1 \\
(3)\end{array}$ & - & - & 333 & 75 & 4,44 \\
\hline 4 & $\begin{array}{l}\text { Perawat dan dokter menyediakan pelayanan } \\
\text { sesuai yang di janjikan }\end{array}$ & $\begin{array}{c}37 \\
(185)\end{array}$ & $\begin{array}{c}37 \\
(148)\end{array}$ & $\begin{array}{c}1 \\
(3)\end{array}$ & - & - & 336 & 75 & 4,48 \\
\hline 5 & $\begin{array}{l}\text { System yang dilakukan oleh zaal kebidanan dan } \\
\text { kandungan terhadap pasien tidak berbelit-belit }\end{array}$ & $\begin{array}{c}36 \\
(180)\end{array}$ & $\begin{array}{c}38 \\
(152)\end{array}$ & $\begin{array}{c}1 \\
(3)\end{array}$ & - & - & 335 & 75 & 4,46 \\
\hline 6 & $\begin{array}{l}\text { Zaal kebidanan dan kandungan konsisten dalam } \\
\text { jadwal yang sudah di tetapkan. }\end{array}$ & $\begin{array}{c}39 \\
(195)\end{array}$ & $\begin{array}{c}35 \\
(140)\end{array}$ & $\begin{array}{c}1 \\
(3)\end{array}$ & - & - & 338 & 75 & 4,50 \\
\hline 7 & $\begin{array}{l}\text { Perawat dan dokter siap sedia membantu para } \\
\text { pasien yang membutuhkan bantuan }\end{array}$ & $\begin{array}{c}39 \\
(195)\end{array}$ & $\begin{array}{c}35 \\
(140)\end{array}$ & $\begin{array}{c}1 \\
(3)\end{array}$ & - & - & 338 & 75 & 4,50 \\
\hline 8 & $\begin{array}{l}\text { Perawat dan dokter selalu merespon permintaan } \\
\text { pasien }\end{array}$ & $\begin{array}{c}33 \\
(165)\end{array}$ & $\begin{array}{c}42 \\
(168)\end{array}$ & - & - & - & 333 & 75 & 4,44 \\
\hline 9 & $\begin{array}{l}\text { Perawat dan dokter memiliki keahlian yang baik } \\
\text { (dengan cepat mengatasi masalah) }\end{array}$ & $\begin{array}{c}37 \\
(185)\end{array}$ & $\begin{array}{c}37 \\
(148)\end{array}$ & $\begin{array}{c}1 \\
(3)\end{array}$ & - & - & 336 & 75 & 4,48 \\
\hline
\end{tabular}




\begin{tabular}{|c|c|c|c|c|c|c|c|c|c|}
\hline 10 & $\begin{array}{l}\text { Perawat dan dokter memiliki pengetahuan dan } \\
\text { keterampilan dalam menjalankan tugasnnya. }\end{array}$ & $\begin{array}{c}36 \\
(180)\end{array}$ & $\begin{array}{c}38 \\
(152)\end{array}$ & $\begin{array}{c}1 \\
(3)\end{array}$ & - & 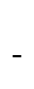 & 335 & 75 & 4,46 \\
\hline 11 & $\begin{array}{l}\text { Perawat dan dokter dapat diandalkan dan dapat } \\
\text { memberikan kepercayaan kepada pasien }\end{array}$ & $\begin{array}{c}33 \\
(165)\end{array}$ & $\begin{array}{c}42 \\
(168)\end{array}$ & - & - & - & 333 & 75 & 4,44 \\
\hline 12 & $\begin{array}{l}\text { Perawat dan dokter peduli akan keinginan } \\
\text { pasien }\end{array}$ & $\begin{array}{c}30 \\
(150)\end{array}$ & $\begin{array}{c}44 \\
(176)\end{array}$ & $\begin{array}{c}1 \\
(3)\end{array}$ & - & - & 329 & 75 & 4,38 \\
\hline 13 & $\begin{array}{l}\text { Perawat dan dokter cepat menanggapi akan } \\
\text { keluhan pasien }\end{array}$ & $\begin{array}{c}30 \\
(150)\end{array}$ & $\begin{array}{c}45 \\
(180)\end{array}$ & - & - & - & 330 & 75 & 4,4 \\
\hline 14 & $\begin{array}{l}\text { Perawat dan dokter menjaga hubungan baik } \\
\text { kepada pasien }\end{array}$ & $\begin{array}{c}27 \\
(135)\end{array}$ & $\begin{array}{c}48 \\
192)\end{array}$ & - & - & - & 327 & 75 & 4,36 \\
\hline \multicolumn{9}{|c|}{ Nilai Rata-Rata Indeks } & 4,48 \\
\hline
\end{tabular}

Sumber: Data Primer yang diolah

Berdasarkan tabel 3 tanggapan responden terhadap kuesioner yang telah disebarkan terhadap pertanyaan-pertanyaan yang di ajukan berkaitan dengan indikator untuk menggambarkan kondisi kualitas pelayanan pada zaal kebidanan dan kandungan rumah sakit umum hamba muara bulian yang nilai indeks ratarata sebesar 4,48 maka mengacu pada retang skala yang di tetapkan maka kondisi kualitas pelayanan pada zaal kebidanan dan kandungan RSUD Hamba Muara Bulian masuk dalam kategori sangat baik.

\section{Kondisi Tingkat Kepuasan Pasien Pada Zaal Kebidanan dan Kandungan RSUD Muara Bulian}

Untuk mengetahui tanggapan pasien tentang tingkat kepuasan pasien pada zaal kebidanan dan kandungan rumah sakit umum hamba muara bulian, peneliti menggunakan daftar pertanyaan yang diajukan kepada responden penelitian yaitu pasien pasa zaal kebidanan dan kandungan RSUD Muara Bulian. Berdasarkan hasil penyebaran kuesioner maka dalam hal ini dirangkum tanggapan pasien mengenai kuesioner tingkat kepuasan pasien:

Tabel 4. Hasil Tanggapan Responden Terhadap Tingkat Kepuasan Pasien

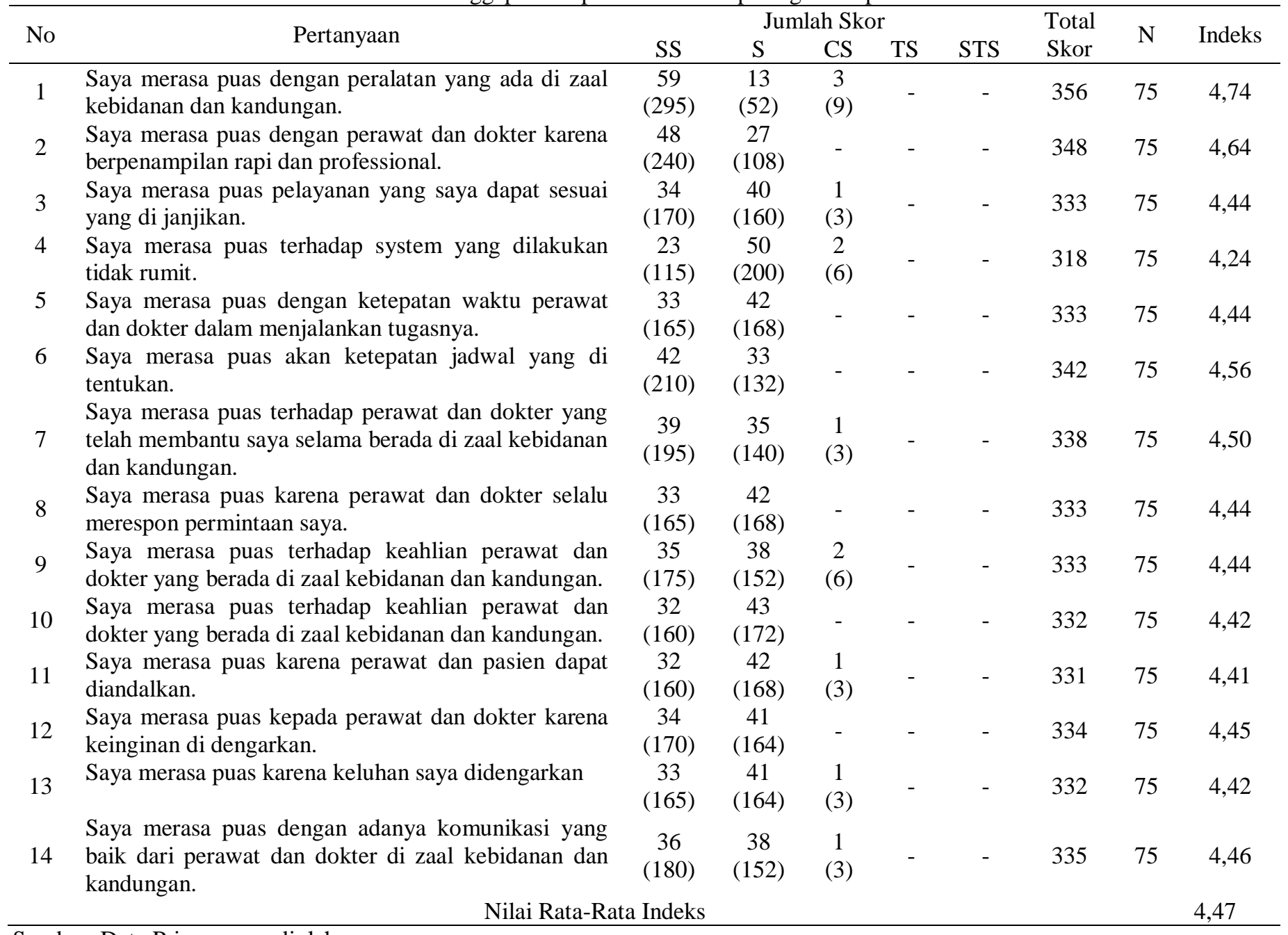


Dari Tabel 4 diatas, berdasarkan tabel tanggapan responden terhadap kuesioner yang telah disebarkan terhadap pertanyaan-pertanyaan yang di ajukan berkaitan dengan indikator untuk menggambarkan tingkat kepuasan pasien pada zaal kebidanan dan kandungan rumah sakit umum hamba muara bulian yang nilai indeks rata-rata 4,47 maka mengacu pada rentang skala yang telah ditetapkan maka kondisi tingkat kepuasan pasien pada zaal kebidanan dan kandungan rumah sakit umum hamba muara bulian berdasarkan esensi jawaban responden masuk dalam kategori sangat tinggi.

\section{SIMPULAN}

Dari Hasil Pembahasan yang sudah disajikan dapat ditarik kesimpulan sebagai berikut: 1) kondisi kualitas pelayanan pada zaal kebidanan dan kandungan pada rumah sakit umum hamba muara bulian diperoleh nilai rata-rata indeks sebesar 4,48 pada rentang skala yang telah ditetapkan maka kondisi kualitas pelayanan pada zaal kebidanan dan kandungan pada rumah sakit umum hamba muara bulian masuk dalam kategori sangat baik. 2) kondisi tingkat kepuasan pasien pada zaal kebidanan dan kandungan pada rumah sakit umum hamba muara bulian diperoleh nilai rata-rata indeks 4,47 pada rentang skala yang ditetapkan maka kondisi tingkat kepuasan pasien pada zaal kebidanan dan kandungan pada rumah sakit umum hamba muara bulian masuk kategori sangat baik.

\section{DAFTAR PUSTAKA}

Arikunto, Suharsimi. 2010. "Prosedur Penelitian". Jakarta : Penerbit PT Rineka Cipta.

Kotler, p., \& Armstrong, G. 2016. Principles ofMarketing, 16th. Prenticel Hall International Inc, New Jersey.

Kotler, p., \& Keller, K. 2016. Marketing management, 15th. Global edition:Pearson Prenticel Hall.

Sugiyono. 2014. Metode Penelitian Kuantitatif dan Kualitatif.. Bandung CV Alfabeta.

Tjiptono. 2015. Strategi pemasaran Yogyakarta:ANDI. 